\title{
Additive Decomposition with Arima Model Forecasts When the Trend Component Is Quadratic
}

\author{
Biu O. Emmanuel1', Dennis Enegesele ${ }^{2}$, C. O. Arimie $^{3}$ \\ ${ }^{1}$ Department of Mathematics \& Statistics, University of Port Harcourt, Port Harcourt, Nigeria \\ ${ }^{2}$ Department of Mathematics and Computing Sciences, KolaDaisi University, Ibadan, Nigeria \\ ${ }^{3}$ Department of Radiology, University of Port Harcourt Teaching Hospital, Port Harcourt, Nigeria \\ Email: emmanuelbiu@yahoo.com, dennis.enegesele@koladaisiuniversity.edu.ng, codarimie@yahoo.com
}

How to cite this paper: Emmanuel, B.O., Enegesele, D. and Arimie, C.O. (2020) Additive Decomposition with Arima Model Forecasts When the Trend Component Is Quadratic. Open Access Library Journal, 7: e6435.

https://doi.org/10.4236/oalib.1106435

Received: May 16, 2020

Accepted: July 10, 2020

Published: July 13, 2020

Copyright $\odot 2020$ by author(s) and Open Access Library Inc.

This work is licensed under the Creative Commons Attribution International License (CC BY 4.0).

http://creativecommons.org/licenses/by/4.0/

\begin{abstract}
This paper demonstrates the use of Buys-Ballot table for identification of decomposition model using graphical method, when the trend cycle component is quadratic. A suitable ARIMA model was fitted, and was used for forecasting. Using the Buys-Ballot techniques, the column means, variances and standard deviation were estimated for the model identification. The additive model had no seasonal effect but, the multiplicative model had seasonal effect. The result of the illustrative example using the data of Nigeria Spot component price of oil (US Dollar per Barrel) showed the additive model to be the appropriate model for decomposition of this series. AR(2) model was identified as a suitable ARIMA model for the de-trended Nigeria Spot component price of oil. This was used to make forecast for the next twelve months. The obtained expected oil prices were compared with the observed prices. The comparison of expected and observed prices showed no significance difference between them, using Mean Absolute Percentage Error (MAPE).
\end{abstract}

\section{Subject Areas}

Applied Statistical Mathematics

\section{Keywords}

Buys-Ballot Table, Seasonal Averages, Column Variances, Trend Analysis, Identification of Model, Decomposition

\section{Introduction}

There are two main reasons for time series analysis: 1) pattern identification of a 
series and 2) forecasting. These goals require that the observed time series data pattern be identified and described [1]. Besides identifying the pattern, the two main reasons will be better evaluated only when the right model is used for the analysis.

Descriptive time series, which is also known as decomposition of time series is the separation of an observed time series into its components represented by the trend $\left(T_{t}\right)$, the seasonal $\left(S_{t}\right)$, cyclical $\left(C_{t}\right)$ and irregular $\left(e_{t}\right)$ components. When the period of time is small, the cyclical component is embedded into the trend and the observed time series $\left(X_{t}, t=1,2, \cdots, n\right)$ can be decomposed into the trend-cycle component $\left(N_{t}\right)$ seasonal component $\left(S_{t}\right)$ and the irregular/residual component $\left(e_{t}\right)[2]$.

There are three main decomposition models in descriptive time series:

Additive Model:

$$
X_{t}=N_{t}+S_{t}+e_{t}
$$

Multiplicative Model:

$$
X_{t}=N_{t} \times S_{t} \times e_{t}
$$

Pseudo-Additive/Mixed Model:

$$
X_{t}=N_{t} \times S_{t}+e_{t}
$$

where, for time point $t, N_{t}$ is the trend-cycle component; $S_{t}$ is the seasonal component and $e_{t}$ is the irregular or random component.

The assumption for the additive model (1) is that the irregular/error component $e_{t}$ is Gaussian $N\left(0, \sigma_{1}^{2}\right)$ white noise and the sum of the seasonal component over a complete period is zero, $\left(\sum_{j=0}^{s} S_{j}=0\right)$ while for the multiplicative model (2), $e_{t}$ is the Gaussian $N\left(1, \sigma_{2}^{2}\right)$ white noise and the sum of the seasonal component over a complete period is $\left(\sum_{j=0}^{s} S_{j}=s\right)$.

The major problem in the use of descriptive time series is the choice of adequate model for time series decomposition. The methods used in the literature to make choice between additive, multiplicative and pseudo-additive models are the graphical and non-graphical methods. In time series where the amplitude of both the seasonal and irregular variations does not change as the level of the trend rises or falls, the additive model is adopted. However, when the amplitude of both the seasonal and irregular variations increases as the level of the trend rises, the multiplicative model is adopted [2]. Iwueze et al. [3] states that using Buys-Ballot table, the relationship between the seasonal means and the seasonal standard deviation could provide an insight of a desired model. In that study, the time plot for means and standard deviation was used for the choice of model.

The method of coefficient of variation of the seasonal quotients and differences was proposed by Justo and Rivera [4]. They opined that if the coefficient of variation for the seasonal quotients is greater than the coefficient of variation for the seasonal differences, the model for decomposition is additive otherwise, and 
the model is multiplicative. This method did not provide the choice and the use of seasonal quotients and a difference was not stated. Iwueze and Nwogu [1] provided a framework for choice of model in descriptive time series based on the Buys-Ballot table. According to them, the column (seasonal) variances of the Buys-Ballot table are simply the trending curve of the time series for the additive model and the product of the trending curve and square of the seasonal effect for the multiplicative model.

The ultimate objective of this paper is to identify and remove trend curve (quadratic) of a time series, using the identified decomposition model (additive or multiplicative model) then, fit an ARIMA model to the de-trended series and use the fitted model for forecasts. The significance of this paper is that it will improve the certainty of the analyst in choosing a suitable model for decomposition of a time series when trend is quadratic.

\section{Method}

\subsection{Buys-Ballot Table}

A Buys-Ballot table gives the summary of time series data arranged in m rows and s column for possible seasonal variation. In other to analyze the data, it is necessary to include the period and seasonal totals $\left(T_{i .}\right.$ and $\left.T_{. j}\right)$, period and seasonal averages $\left(\bar{X}_{i .}\right.$ and $\left.\bar{X}_{. j}\right)$, the grand total and mean $\left(T_{. .}\right.$and $\left.\bar{X}_{. .}\right)$. Wold [5] credits these arrangements of time series data to Buys-Ballot [6] hence, the table is referred to as Buys-Ballot table in the literature and is as shown in Table 1. In Table 1 below, the rows represent the periods/years while the column are the seasons.

For better understanding of Table 1, we have defined the column $(j)$ totals, averages and standard deviation as follows:

Table 1. Buys-ballot table.

\begin{tabular}{cccccccccc}
\hline \multirow{2}{*}{ Period $(i)$} & \multicolumn{10}{c}{ Seasons } \\
\cline { 2 - 10 } & 1 & 2 & $\ldots$ & $j$ & $\ldots$ & $s$ & $T_{i .}$ & $\bar{X}_{i .}$ & $\hat{\sigma}_{i .}$ \\
\hline 1 & $X_{1}$ & $X_{2}$ & $\ldots$ & $X_{j}$ & $\ldots$ & $X_{s}$ & $T_{1 .}$ & $\bar{X}_{1 .}$ & $\hat{\sigma}_{1}$ \\
2 & $X_{s+1}$ & $X_{s+2}$ & $\ldots$ & $X_{s+j}$ & $\ldots$ & $X_{2 s}$ & $T_{2 .}$ & $\bar{X}_{2 .}$ & $\hat{\sigma}_{2}$ \\
3 & $X_{2 s+1}$ & $X_{2 s+2}$ & $\ldots$ & $X_{2 s+j}$ & $\ldots$ & $X_{3 s}$ & $T_{3 .}$ & $\bar{X}_{3 .}$ & $\hat{\sigma}_{3}$ \\
$\ldots$ & $\ldots$ & $\ldots$ & $\ldots$ & $\ldots$ & $\ldots$ & $\ldots$ & $\ldots$ & $\ldots$ & $\ldots$ \\
$i$ & $X_{(i-1) s+1}$ & $X_{(i-1) s+2}$ & $\ldots$ & $X_{(i-1) s+j}$ & $\ldots$ & $X_{(i-1) s+s}$ & $T_{i .}$ & $\bar{X}_{i .}$ & $\hat{\sigma}_{i .}$ \\
$\ldots$ & $\ldots$ & $\ldots$ & $\ldots$ & $\ldots$ & $\ldots$ & $\ldots$ & $\ldots$ & $\ldots$ & $\ldots$ \\
$m$ & $X_{(m-1) s+1}$ & $X_{(m-1) s+2}$ & $\ldots$ & $X_{(m-1) s+j}$ & $\ldots$ & $X_{m s}$ & $T_{m .}$ & $\bar{X}_{m .}$ & $\hat{\sigma}_{m .}$ \\
$T_{. j}$ & $T_{.1}$ & $T_{.2}$ & $\ldots$ & $T_{. j}$ & $\ldots$ & $T_{. s}$ & $T_{. .}$ & - & - \\
$\bar{X}_{. j}$ & $\bar{X}_{.1}$ & $\bar{X}_{.2}$ & $\ldots$ & $\bar{X}_{. j}$ & $\ldots$ & $\bar{X}_{. s}$ & - & $\bar{X}_{. .}$ & - \\
$\hat{\sigma}_{. j}$ & $\hat{\sigma}_{.1}$ & $\hat{\sigma}_{.2}$ & $\ldots$ & $\hat{\sigma}_{. j}$ & $\ldots$ & $\hat{\sigma}_{. s}$ & - & - & $\hat{\sigma}_{. .}$ \\
\hline
\end{tabular}

Source: Iwueze and Nwogu [1]. 


$$
\begin{gathered}
T_{. j}=\sum_{i=1}^{m} X_{(i-1) s+j}, \quad i=1,2, \cdots, s \\
\bar{X}_{. j}=\frac{T_{. j}}{m}=\frac{1}{m} \sum_{i=1}^{m} X_{(i-1) s+j}, \quad j=1,2, \cdots, s \\
\hat{\sigma}_{. j}=\sqrt{\frac{1}{m-1} \sum_{i=1}^{m}\left(X_{(i-1) s+j}-\bar{X}_{. j}\right)^{2}}, j=1,2, \cdots, s
\end{gathered}
$$

where $X_{t}, t=1,2, \cdots, n$ is the series, $m$ is the number of periods/years, $s$ is the periodicity, and $n=m s$ is the overall number of observation/sample size.

$T_{. j}=$ Total for $j$ th season, $\bar{X}_{. j}=$ Average of $j$ th season

$\hat{\sigma}_{. j}=$ Standard deviation for $j$ th season.

Let, $X_{t}=a+b t+c t^{2}+S_{t}+e_{t}$ be the observation of the time series at time, $t$.

Define $\bar{X}_{. j}$ as column mean and $\sigma_{. j}^{2}$ as column variances for additive model.

We can write $t=(i-1) s+j$ in terms of the row $(i)$ and column $(j)$ of the Buys-Ballot table.

For the multiplicative model:

Let, $X_{t}=\left(a+b t+c t^{2}\right) * S_{t} * e_{t}$ be the observation of time series at time, $t$.

Define $\bar{X}_{. j}$ as column mean and $\sigma_{. j}^{2}$ as column variances for multiplicative model.

We can write $t=(i-1) s+j$ in terms of the row $(i)$ and column $(j)$ of the Buys-Ballot table [3].

Several papers in the statistics literature have discussed the use of time plot of the entire series to make the appropriate choice between additive and multiplicative models. This makes a review of some of the works done as regards the choice of models in a descriptive time series analysis necessary in order to highlight the import of this study.

The time plot of a series can be used to choose between additive and multiplicative models. If the seasonal variation stays roughly the same size regardless of the mean level, then it is additive, but if it increases in size in direct proportion to the mean level, then it is said to be multiplicative [2].

Iwueze et al. [3] on the uses Buys-Ballot table, states that the relationship between the seasonal means and the seasonal standard deviation could give an indication of a desired model. Additive model should be employed when the seasonal standard deviation shows no applicable increase/decrease relative to any increase or decrease in the seasonal means. The multiplicative model should be employed when the seasonal standard deviation shows applicable increase/decrease relative to any increase or decrease in the seasonal means. This comparison was done using time plot for means and standard deviation.

Figures 1-4 respectively illustrate two (2) time series with their trend components, on which the choice of appropriate model can be easily decided. In the first case, the additive model was the appropriate choice as the differences between the trend and observed data (the seasonal differences) for the same periods in different years are almost the same, while in the second case the multiplicative 


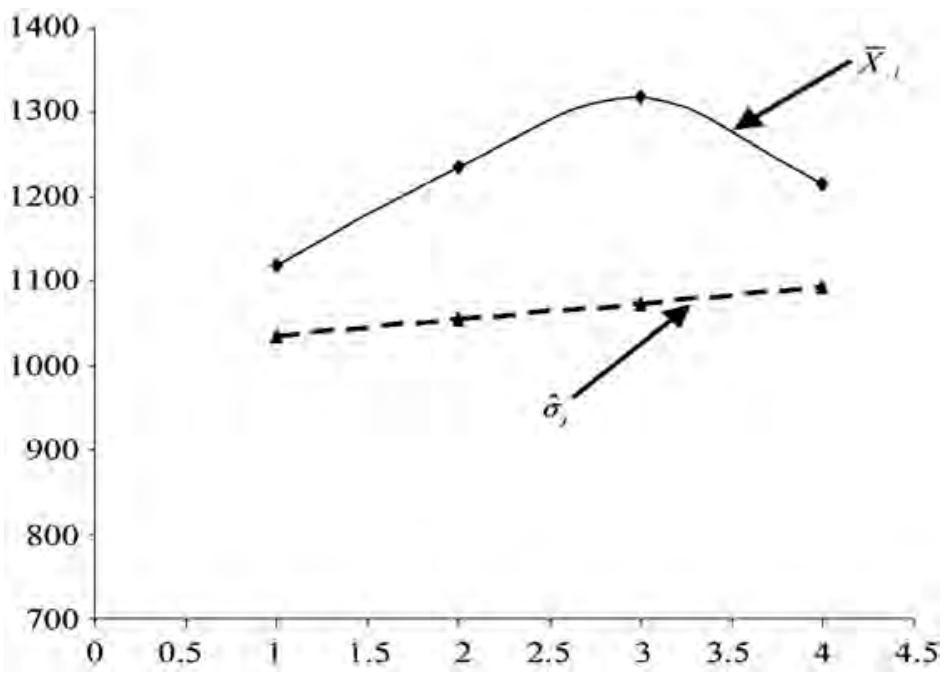

Figure 1. Additive model with non-seasonal effect.

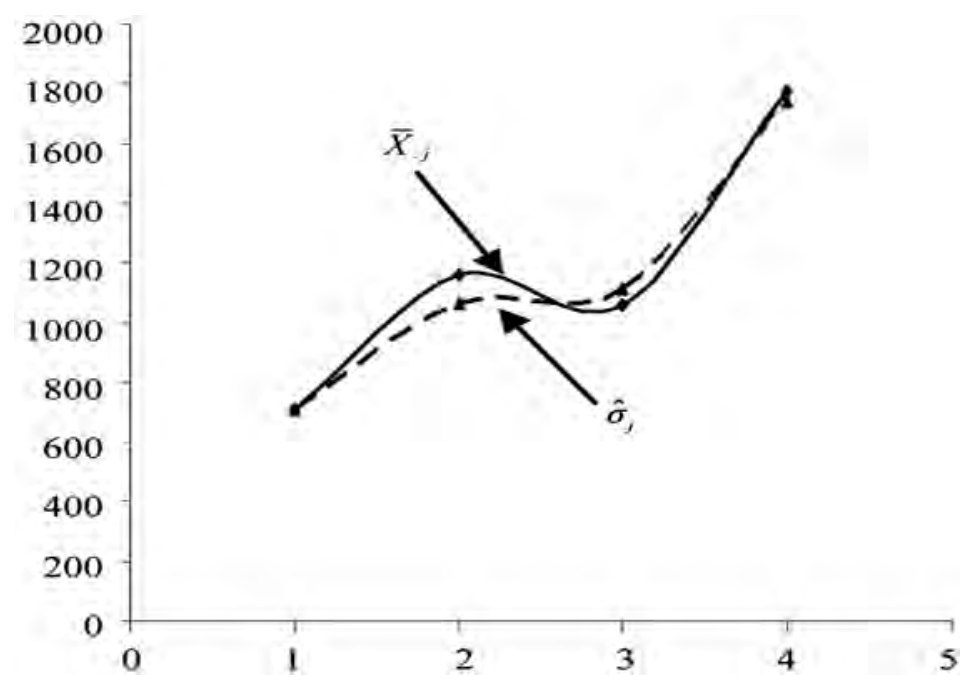

Figure 2. Multiplicative model with non-seasonal effect.

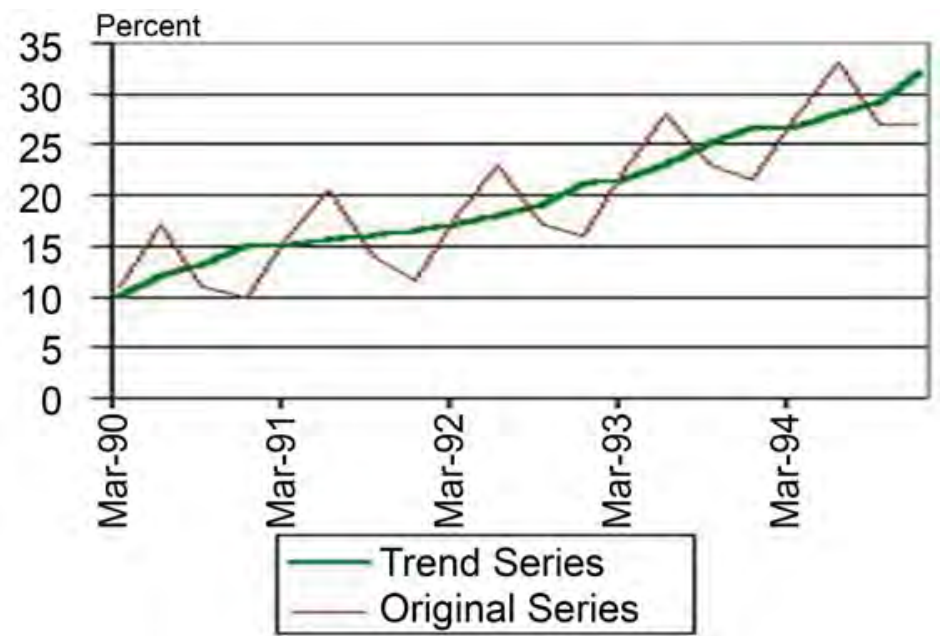

Figure 3. Time series appropriate for additive decomposition with seasonal effect. 


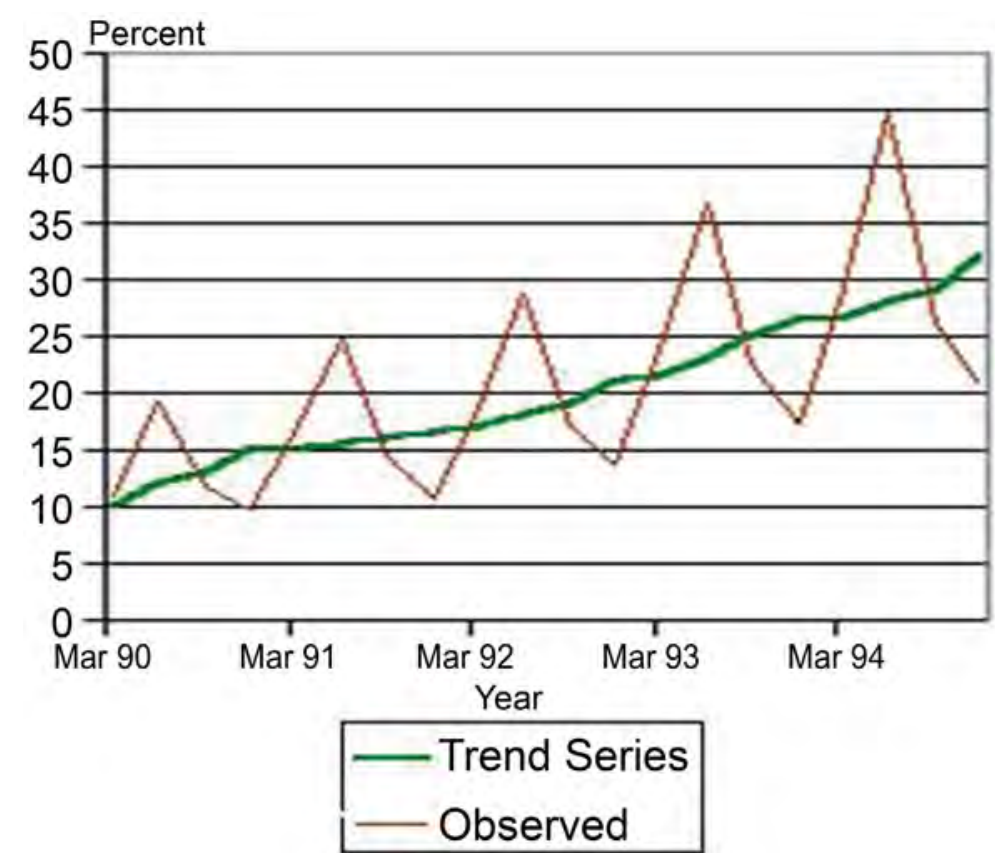

Figure 4. Time series appropriate for multiplicative decomposition with seasonal effect. Source:

http://www.stats.govt.nz/surveys_and_methods/methods/data-analysis/seasonal-adjustm ent/theunderlying-model.aspx.

model was chosen, because the ratios of the trend and observed data (the seasonal indices) for the same periods in different years are almost the same. Thus, the appropriate model is either additive or multiplicative.

\subsection{Autoregressive Moving Average (ARMA) Model}

Frequently, after achieving stationarity, a time series contains $\operatorname{AR}(p)$ and $\operatorname{MA}(q)$ components of certain orders which can be combined and used for forecasting. It can also be called mixed process. Thus, a mixture of autoregressive process of order $p, \operatorname{AR}(p)$, and moving average of order $q, \operatorname{MA}(q)$, denoted as $\operatorname{ARMA}(p, q)$, is of the form;

$$
\begin{gathered}
X_{t}=\phi_{1} X_{t-1}+\phi_{2} X_{t-2}+\cdots+\phi_{p} X_{t-p}+e_{t}+\theta_{1} e_{t-1}+\theta_{2} e_{t-2}+\cdots+\theta_{q} e_{t-q} \\
X_{t}-\phi_{1} X_{t-1}-\phi_{2} X_{t-2}-\cdots-\phi_{p} X_{t-p}=e_{t}+\theta_{1} e_{t-1}+\theta_{2} e_{t-2}+\cdots+\theta_{q} e_{t-q} \\
\left(1-\phi_{1} B-\phi_{2} B^{2}-\cdots-\phi_{p} B^{p}\right) X_{t}=\left(1+\theta_{1} B+\theta_{2} B^{2}+\cdots+\theta_{q} B^{q}\right) e_{t} \\
\phi(B) X_{t}=\theta(B) e_{t}
\end{gathered}
$$

where, $\phi(B)=1-\phi_{1} B-\phi_{2} B^{2}-\cdots-\phi_{p} B^{p}$ and $\theta(B)=1+\theta_{1} B+\theta_{2} B^{2}+\cdots+\theta_{q} B^{q}$ and $e_{t}$ is a sequence of independently and identically distributed (iid) random variables with $E\left(e_{t}\right)=0$ and $\operatorname{Var}\left(e_{t}\right)=\sigma_{e}^{2}$.

For stationarity, the roots of $\phi(B)=0$ lie outside the unit circle and for invertibility condition, the roots of $\theta(B)=0$ all lie outside the unit circle.

For the $\operatorname{ARMA}(p, q)$ process, there are $q$ autocorrelations, $\rho_{1}, \rho_{2}, \cdots, \rho_{q}$ whose values depend directly on the choice of the $q$ moving average parameters 
$\theta_{1}, \theta_{2}, \cdots, \theta_{q}$, as well as on the $p$ autoregressive parameters $\phi_{1}, \phi_{2}, \cdots, \phi_{q}$.

\subsubsection{Model Selection Criteria}

When more than one model is selected from the process enumerated in Equation (8), the Akaike's Information Criterion (AIC) is then used to select the most suitable model amongst them. The Akaike's Information Criterion is most commonly given as:

$$
\mathrm{AIC}=N \log \hat{\sigma}^{2}+2 r
$$

where, $r$ is the number of model parameters, $N=$ Effective number of data point used in the estimation procedure and $\hat{\sigma}^{2}$ is the estimated residual variance (Mean sum of squared error (MSE)) [7] [8]. The model that minimizes the AIC criterion is the best model.

\subsubsection{Accuracy Measures of the Estimated Values}

\section{1) Estimated Errors}

To gauge the accuracy of our estimates, the estimated errors will be used to compare the expected estimated forecast values and observed values for 2013 . This is done by subtracting the estimated forecast values (EFV) from the original values or [actual values (AV)] to obtain the estimate errors [9]. The estimate error $\left(e_{i}\right)$ is denoted by

$$
e_{i}=\mathrm{AV}_{i}-\mathrm{EFV}_{i}, i=1,2, \cdots, v
$$

However, the accurate measures used in this paper are Mean Absolute Percentage Error (MAPE).

\section{2) Mean Absolute Percentage Error (MAPE)}

This accounts for the percentage of deviation between the actual values and estimates [10]. This can be obtained as:

$$
\mathrm{MAPE}=100 \times\left[\frac{1}{v} \sum_{i=1}^{v} \frac{e_{i}}{\mathrm{AV}_{i}}\right] \quad\left(\mathrm{AV}_{i} \neq 0\right)
$$

where, $v$ is the number of forecast values.

This method is now illustrated in Section 3.0 with the use of real-life time series data.

\section{Empirical Illustration}

The section is divided into two parts: 1) Identifying between additive or multiplicative model for time series decomposition. 2) ARIMA model and forecasting.

\subsection{Identification of Additive or Multiplicative Model}

Nigeria Spot component price of oil (US Dollar per Barrel) from 1983-2013 data (Appendix A) was applied to the Buys-Ballot table to ascertain if the additive or multiplicative models should be used for Time Series decomposition. The column means, variances and standard deviation were obtained. Then, the trend behaviour using means and standard deviation is shown below in Figure 5. 


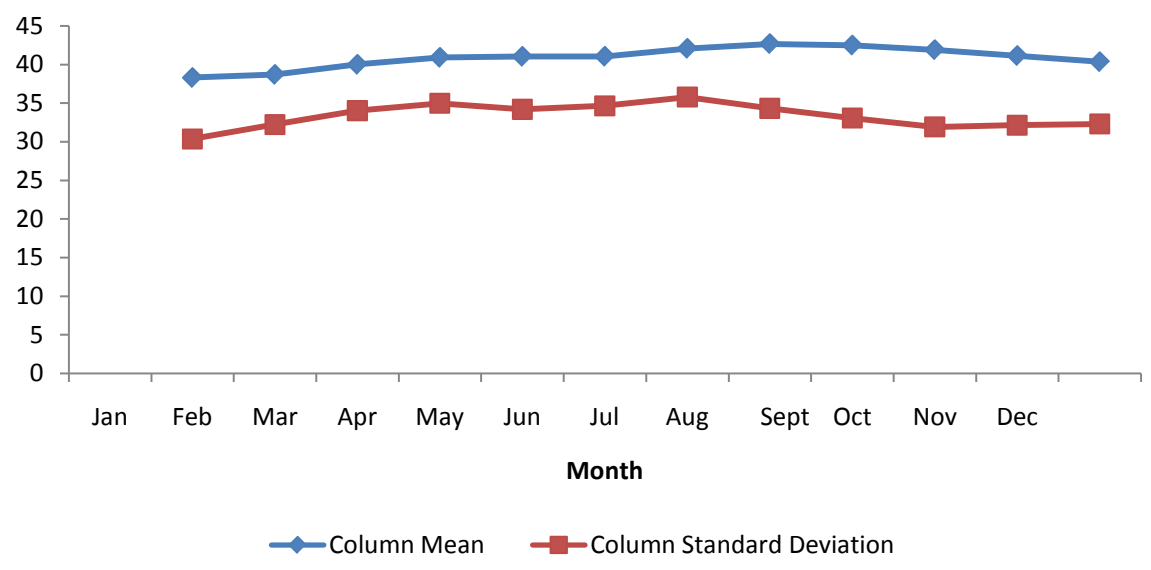

Figure 5. decomposition model identification.

The time plot for means and standard deviation in Figure 5 was used for the choice of model. Figure 5 show that the standard deviation variation stays roughly the same size regardless of the mean level, which implies additive [2]. Thus, the appropriate model for decomposition Nigeria Spot component price of oil (US Dollar per Barrel) is the additive model.

\subsection{ARMA Model and Forecasting}

This section is divided into three parts: de-trend the series using the appropriate model for decomposition (i.e. additive model), ARMA modeling of the series and Forecasting.

Data: Nigeria Spot component price of oil (US Dollar per Barrel) (1983-2013)

The Nigeria Spot component price of oil (US Dollar per Barrel) is a monthly data comprising 372 data points given in 31 years (1983-2013). Appendix A shows a complete presentation of the data in Buys-Ballot table form and its series plot is shown as Figure 6. Note that the first 30 years (1983-2012) was used for model building $\left(X_{t}\right)$ and the last year (2013) was used for forecasts comparison.

Examining Figure 6, we noticed that NSCPO series appreciate from January 1983 to December 2012, which indicate a trend component which is either any of the polynomials of suitable order. Hence, we fitted several polynomials trend curve of order $m_{0}$ in other to identify which curve represents the trend component in the NSCPO series, using $R$-square $\left(R^{2}\right)$ ([11] [12] [13]). The polynomial trend that $R^{2}$ is close to 1 , with its entire coefficient being significant is the best trend curve.

\subsubsection{Trend Identification and the De-Trended Series}

The general polynomial trend is expressed as:

$$
\hat{X}_{t}=\hat{C}_{0}+\hat{C}_{1} t+\hat{C}_{2} t^{2}+\cdots+\hat{C}_{m} t^{m}
$$

where, $m$ is the order of the fitted polynomial at which $R^{2}$ is close to 1 .

We used Equation (12) to estimate the coefficients of the polynomials, $C_{k}, k=1,2, \cdots, m$ in Figure 7 using Microsoft Excel. Then, we also used regression 


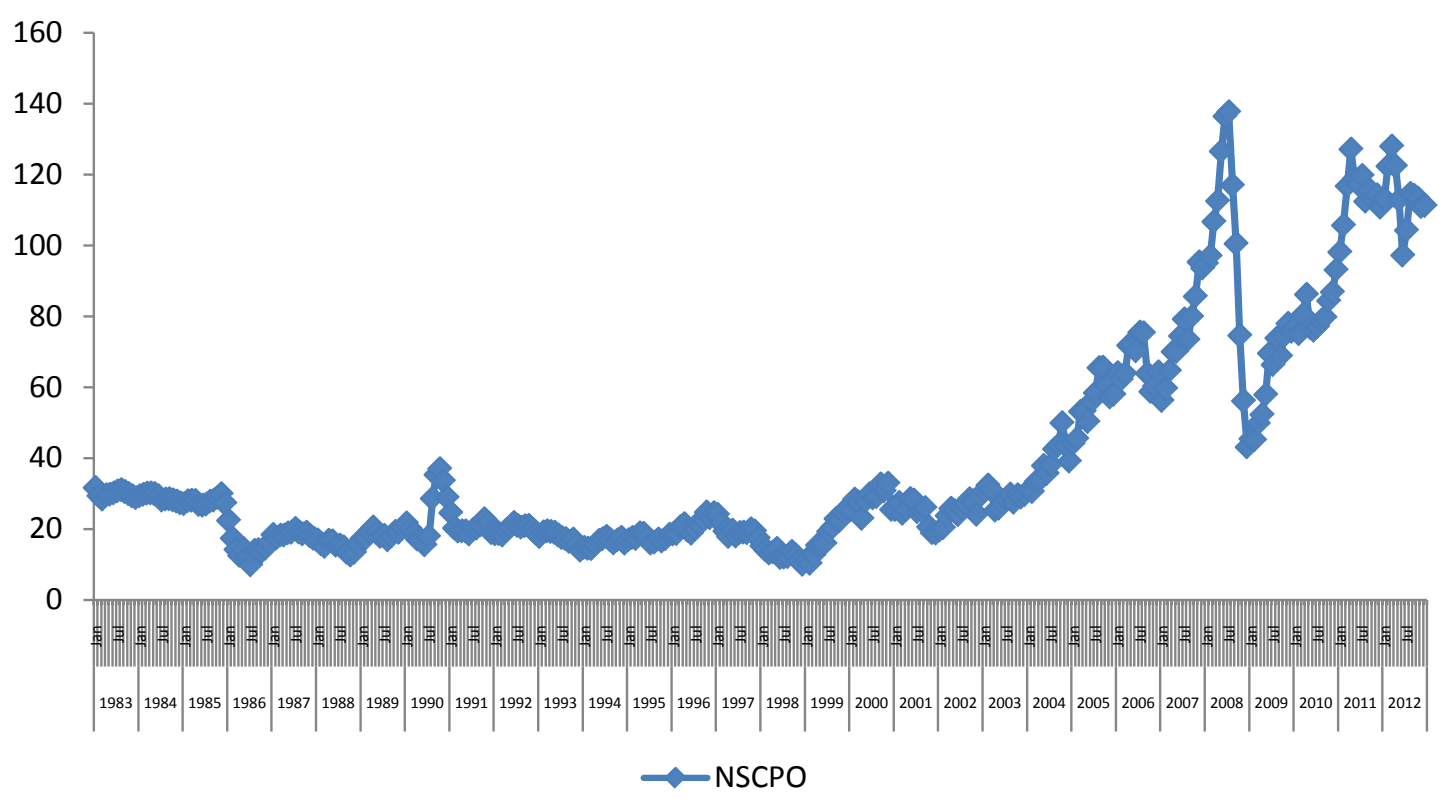

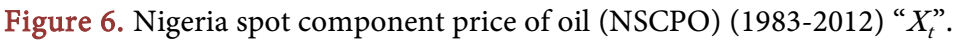

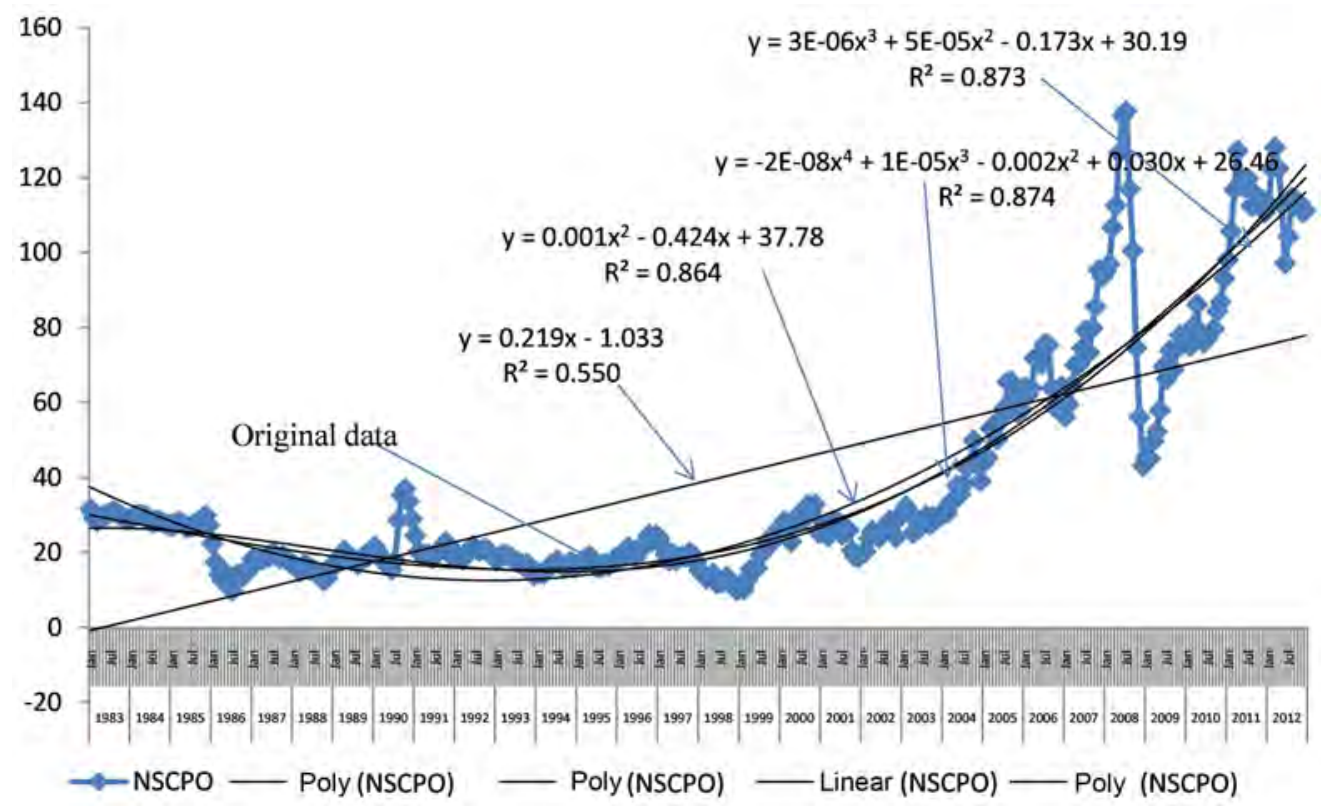

Figure 7. Trend curves fitted to NSCPO series $\left(X_{t}\right)$.

method to fit the coefficients of the polynomials of order $\mathrm{m}$ with the help of Minitab 17 in Appendix B, summarized in Table 2.

From Table 2, one of the estimated coefficients of the polynomial of order 3 is not significant and two estimated coefficients of the polynomial of order 4 are also not significant. However, when these coefficients are remove from the fitted polynomial trend curve, the resultant trend curve is quadratic as shown in Table 2 above (Hint: over fitting method). Therefore, the best fitted polynomial trend curve is quadratic trend with $R^{2}=0.86 \%$. Another reason why the polynomials of order three and four cannot be used for this analysis is that they fit negative 
Table 2. Fitted polynomials of the NSCPO series.

\begin{tabular}{|c|c|c|c|c|c|c|c|}
\hline \multirow{2}{*}{ order $m$} & \multicolumn{5}{|c|}{ Estimated Coefficients ( $p$-values) } & \multirow{2}{*}{$R^{2}$} & \multirow{2}{*}{ REMARK } \\
\hline & $\hat{C}_{0}$ & $\hat{C}_{1}$ & $\hat{C}_{2}$ & $\hat{C}_{3}$ & $\hat{C}_{4}$ & & \\
\hline 1 & $\begin{array}{l}-1.033 \\
(0.636)\end{array}$ & $\begin{array}{c}0.219 \\
(0.000)\end{array}$ & & & & $55.0 \%$ & Linear Trend \\
\hline 2 & $\begin{array}{l}37.781 \\
(0.000)\end{array}$ & $\begin{array}{c}-0.4242 \\
(0.000\end{array}$ & $\begin{array}{c}1.782 \times 10^{-3} \\
(0.000)\end{array}$ & & & $86.4 \%$ & $\begin{array}{c}\text { Quadratic } \\
\text { trend }\end{array}$ \\
\hline 3 & $\begin{array}{l}30.198 \\
(0.000)\end{array}$ & $\begin{array}{c}-0.1739 \\
(0.000)\end{array}$ & $\begin{array}{c}5.07 \times 10^{-5} \\
(0.888)^{\star *}\end{array}$ & $\begin{array}{c}3.20 \times 10^{-6} \\
(0.000)\end{array}$ & & $87.30 \%$ & Cubic Trend \\
\hline 4 & $\begin{array}{l}26.462 \\
(0.000)\end{array}$ & $\begin{array}{c}0.0305 \\
(0.786)^{* *}\end{array}$ & $\begin{array}{l}-0.0025 \\
(0.05)^{\star *}\end{array}$ & $\begin{array}{c}1.413 \times 10^{-5} \\
(0.000)\end{array}$ & $\begin{array}{c}-2.0 \times 10^{-8} \\
(0.036)\end{array}$ & $87.4 \%$ & Quartic trend \\
\hline
\end{tabular}

Footnote: ${ }^{* *}$-values are greater than the appropriate critical value $(0.05)$ and the bold trend is the optimal order $(m=2)$ identified.

values to values that are positive. Thus, we conclude that the trend component is represented by the quadratic trend curve.

The fitted polynomial (quadratic trend; $m=2$ ) is given as

$$
\hat{X}_{t}=C_{0}+C_{1} t+C_{2} t^{2}
$$

By substitution of the coefficients in Table 2 into Equation (13), we have

$$
\hat{X}_{t}=37.781-0.4242 t+\left(1.782 \times 10^{-3}\right) t^{2} ; t=1,2, \cdots, 360
$$

Next, we used the additive model identified in removing the trend of the NSCPO Series since the trend curve is the quadratic. The identified model decomposition process is the additive model in Section 3.1 and Equation (1) is the representation of the additive model.

- Additive Model Decomposition:

$$
Y_{t}=X_{t}-\hat{X}_{t}, t=1,2, \cdots, 360
$$

Then,

$$
Y_{t}=X_{t}-\left(37.781-0.4242 t+\left(1.782 \times 10^{-3}\right) t^{2}\right), t=1,2, \cdots, 360
$$

Figure 8 shows that the series is stationary and the variance is constant which indicated that the quadratic trend have been removed completely by the use of Equation (16) [or by the Additive Method.]. We now fit the best $\operatorname{ARMA}(p, q)$ model to the de-trended series [represented by (16)].

\subsubsection{ARMA Modelling of the Series (16)}

From Figure 8 above, the autocorrelation function (ACF) and partial autocorrelation function (PACF) are shown in Figure 9 and Figure 10, respectively.

Figure 9 show significant spikes at lags 1,2, 3, 4 and 5 while Figure 10 showed significant spikes at lags 1 and 2 only. Figure 9 suggests MA(5) while Figure 10 suggest $\operatorname{AR}(2)$ process. However, suitable $\operatorname{ARMA}(p, q)$ models $(p+q \leq 5)$ may also be appropriate.

On the other hand, a test is appropriate, to test if the constant mean " $\mu$ " be included in the models. In this case, the hypothesis of interest is given as 


\section{Additive Yt}

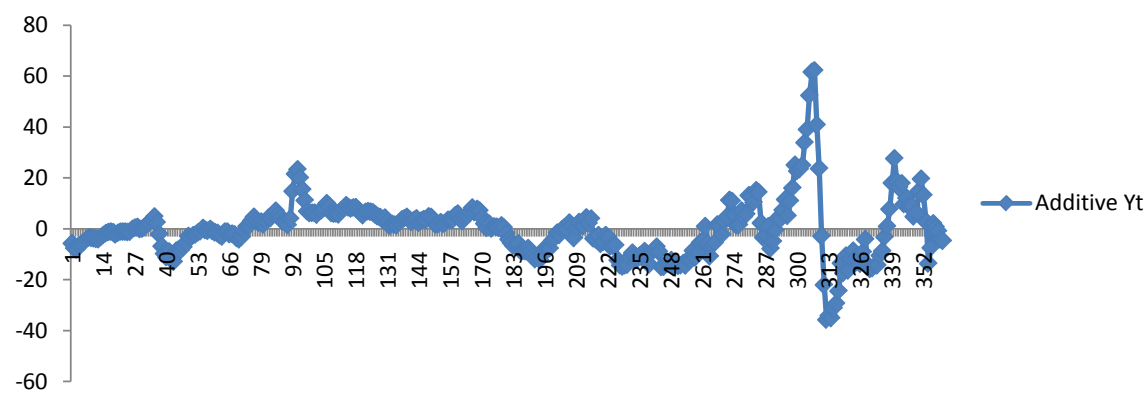

Figure 8. De-trended series of the NSCPO series $\left(Y_{t}\right)$.

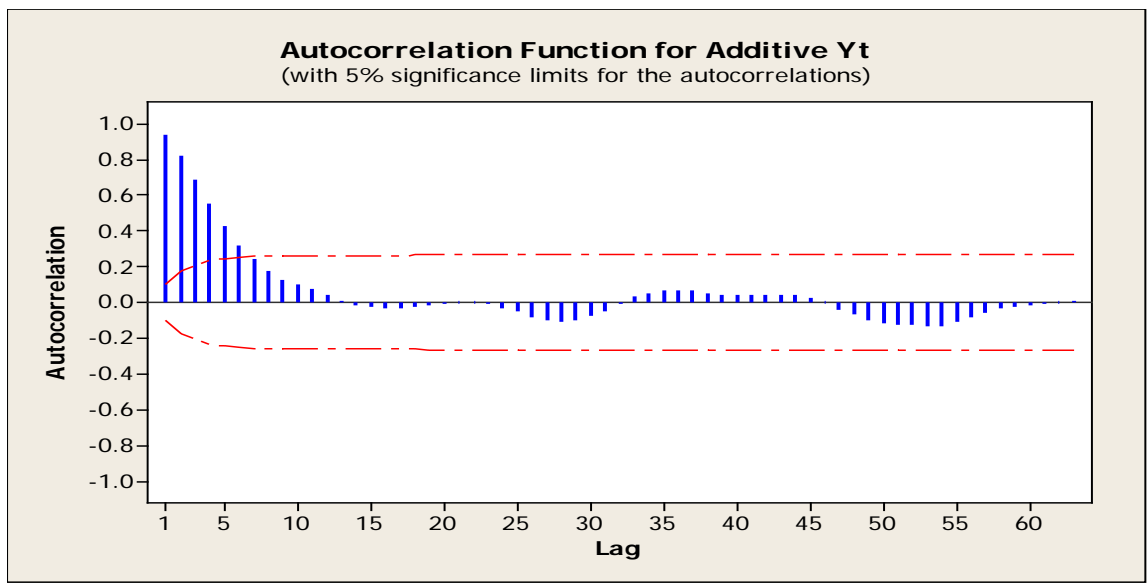

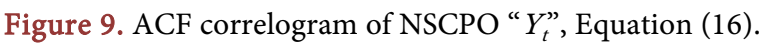

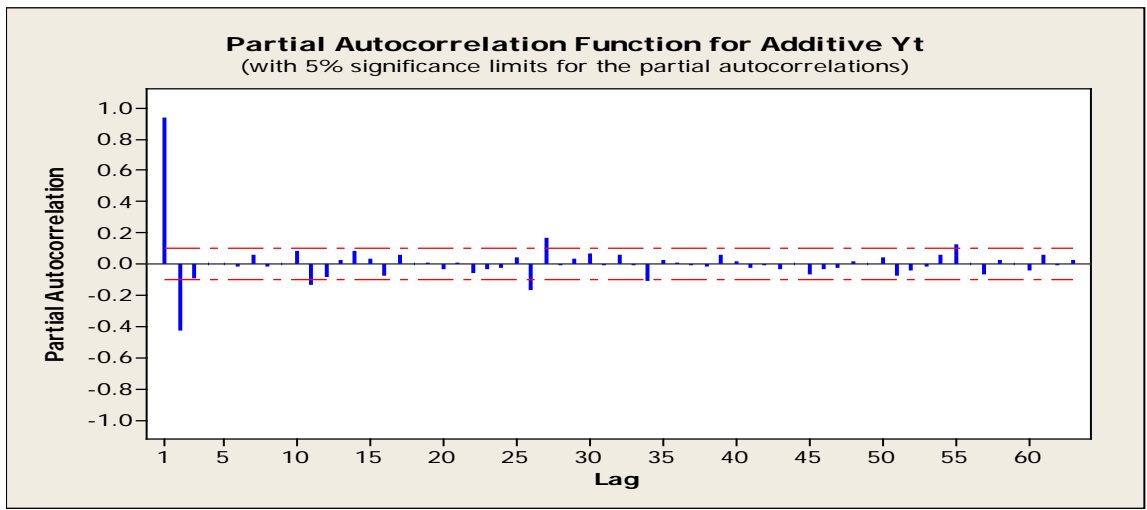

Figure 10. PACF correlogram of NSCPO “ $Y_{t}$ ”, Equation (16).

$$
H_{0}: \mu=0 \text { against } H_{1}: \mu \neq 0
$$

The test statistics for testing $H_{0}: \mu=0$ against $H_{1}: \mu \neq 0$ is

$$
t=\frac{\bar{Y}_{t}}{s t d\left(Y_{t}\right)}
$$

The computed t-value is $t=-9.32 \times 10^{-7}$ with $p$-value $=1.000$ (see Appendix C). This $p$-value is greater than the critical $p$-value $=0.05$ hence, we accepted $H_{0}: \mu=0$. This implies that $\mu$ should not be included in the model. 
Various $\operatorname{ARMA}(p, q)$ models were fitted to Equation (16) with respective residuals being white noise and the summary is shown in Table 3. The model selection criteria used to select the best model amongst models is Akaike's Information Criterion (AIC) [Section 2.2.1, Equation (17)] is also detailed out in $\mathrm{Ta}$ ble 3 .

The identified model using Akaike's Information Criterion in Table 3 is $\operatorname{AR}(2)$ model. AR(2) can be expressed as

$$
Y_{t}=\phi_{1} T_{t-1}+\phi_{1} Y_{t-2}+e_{t}
$$

\section{Estimation of the Parameter of the Identified AR(2) for (16)}

Estimates were obtained by use of Minitab 17 software and the results are tabulated in Table 4.

The residuals ACF and PACF in Figure 11 and Figure 12 reveal that the model is adequate for Equation (16). The adequacies of the model were also checked by the use of Ljung-Box Chi-square statistics [14], and the results are summarized in Table 5.

Table 3. AIC values for $\operatorname{ARMA}(p, q)$ models $(p+q \leq 5)$.

\begin{tabular}{ccccc}
\hline Model & $r$ & $\sigma^{2}$ & $\boldsymbol{N}$ & AIC \\
\hline $\operatorname{AR}(1)$ & 1 & 16.03 & 360 & 1000.81 \\
$\operatorname{AR}(2)$ & 2 & 13.09 & 360 & 929.87 \\
$\operatorname{MA}(5)$ & 5 & 14.12 & 360 & 963.13 \\
$\operatorname{ARMA}(1,1)$ & 2 & 13.81 & 360 & 949.14 \\
$\operatorname{ARMA}(1,2)$ & 3 & 13.24 & 360 & 935.97 \\
$\operatorname{ARMA}(1,3)$ & 4 & 13.15 & 360 & 935.51 \\
$\operatorname{ARMA}(1,4)$ & 5 & 13.14 & 360 & 937.24 \\
$\operatorname{ARMA}(1,5)$ & 6 & 13.05 & 360 & 936.76 \\
\hline
\end{tabular}

Table 4. Parameter estimates of AR(2) Model for (16).

\begin{tabular}{c}
\hline $\operatorname{AR}(2)$ Model \\
$\varphi_{1}=0.3389 \pm 0.0477$ \\
$\varphi_{2}=-0.4315 \pm 0.0477$ \\
$\sigma^{2}=13.09$ \\
\hline
\end{tabular}

Footnote: values after $( \pm)$ are their standard errors.

Table 5. (Ljung-box) chi-square statistic for adequacy of (19).

\begin{tabular}{cccc}
\hline$k$ & $d f$ & $\operatorname{AR}(2)$ & Chi-square Table $\chi_{(h)}^{2}$ \\
\cline { 3 - 4 } 12 & 10 & $Q(k)$ & 18.3 \\
24 & 22 & 32.8 & 33.9 \\
36 & 34 & 55.3 & 58.8 \\
48 & 46 & 67.0 & 67.5 \\
\hline
\end{tabular}

Footnote: $k$ is the lags. 


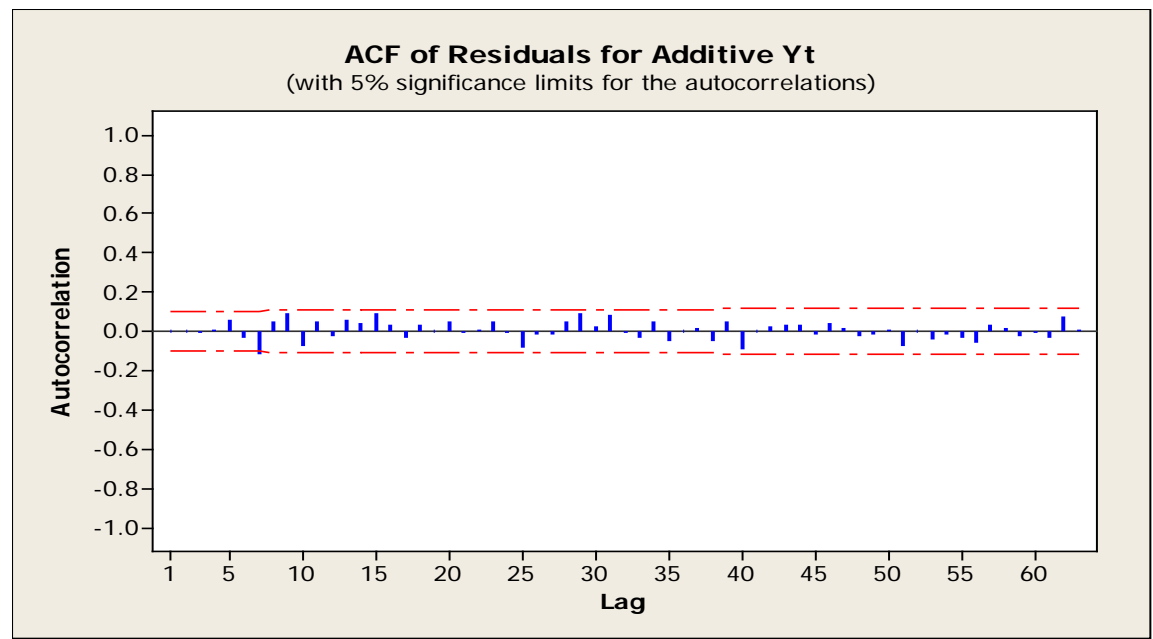

Figure 11. Residual ACF correlogram of AR(2).

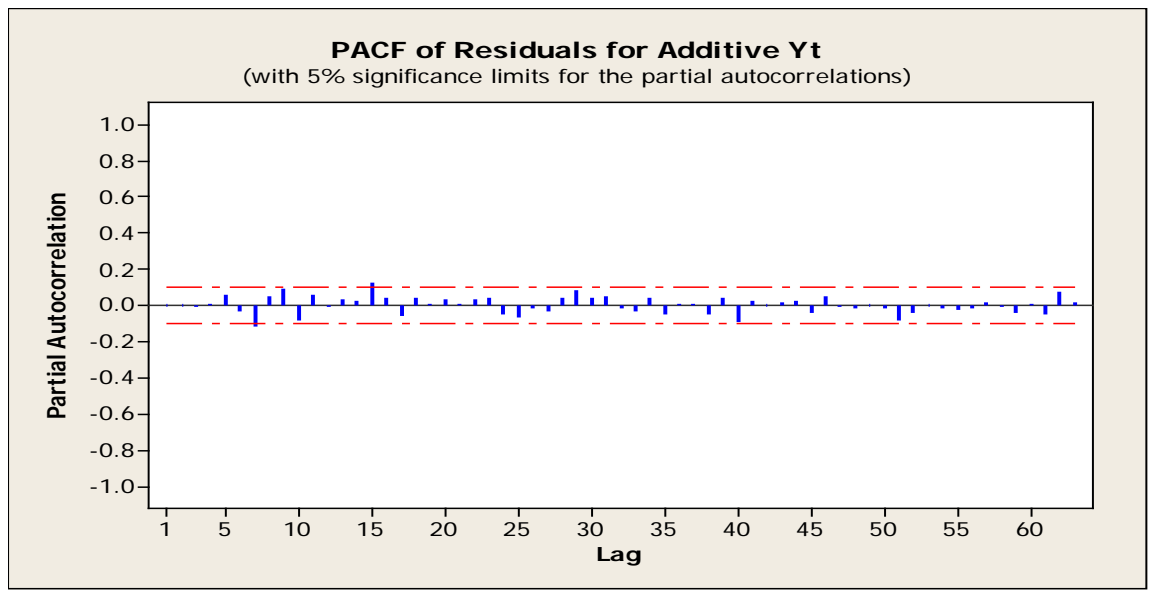

Figure 12. Residual PACF correlogram of AR(2).

In Table 5, comparing $Q(k)$ with $X_{(d f)}^{2}$, [i.e. $Q(k)<X_{(d f)}^{2}, k=12,24,36,48$ ], it is obvious that the model is adequate and they can be used for forecasting.

\subsubsection{Forecasting}

We obtained forecasts for AR(2) model in Equation (19) starting at the origin point 360 for 12 months. The $\ell$-step forecasts denoted by $\hat{Y}_{t}\left(\ell_{i}\right)$ for $i=1,2, \cdots, 12$ with the $95 \%$ confidence intervals of the forecasts are shown in Appendix D. Similarity the forecasts values using Equation (19) was obtained. The expected estimated forecast values for NSCPO Series $\left(X_{t}\right)$; i.e. $\left(X_{t}=Y_{t}+\hat{X}_{t}\right)$ and the estimated error $\left(e_{i}\right)$ between actual values for the year 2013 and the expected estimated forecast values, using Equation (14) are shown in Table 6.

In Table 6 below, the accuracy measures of the estimated forecasts confirmed that additive model is the suitable method, because it is closer to the original values for 2013. [Hint: using the MAPE accuracy measure, the additive decomposition method shows $8.64 \%$ (or $9 \%$ ) less than the original values for the year 2013). 
Table 6. Comparison of forecast values obtained by Equation (14) and Equation (19) with the original values for 2013 .

\begin{tabular}{|c|c|c|c|c|c|c|}
\hline \multirow[b]{2}{*}{$\begin{array}{c}\text { Period } \\
\quad(t)\end{array}$} & \multirow[b]{2}{*}{ Months } & \multirow[b]{2}{*}{ Actual (2013) } & \multicolumn{3}{|c|}{ Expected estimated Forecast Values } & \multirow[b]{2}{*}{ Estimated Errors " $e_{i}$ " } \\
\hline & & & $\begin{array}{c}\operatorname{AR}(2) \\
Y_{t}\end{array}$ & $\begin{array}{c}\text { Quadratic } \\
\text { Trend } \\
\hat{X}_{t}\end{array}$ & $\left(X_{t}=Y_{t}+\hat{X}_{t}\right)$ & \\
\hline 361 & January & 115.41 & -4.6296 & 116.88 & 112.25 & 3.16 \\
\hline 362 & February & 118.69 & -4.1159 & 117.74 & 113.62 & 5.07 \\
\hline 363 & March & 110.57 & -3.5135 & 118.61 & 115.10 & -4.53 \\
\hline 364 & April & 105.17 & -2.9284 & 119.48 & 116.55 & -11.38 \\
\hline 365 & May & 105.83 & -2.4050 & 120.36 & 117.96 & -12.13 \\
\hline 366 & June & 106.12 & -1.9566 & 121.24 & 119.28 & -13.16 \\
\hline 367 & July & 110.21 & -1.5821 & 122.12 & 120.54 & -10.33 \\
\hline 368 & August & 113.62 & -1.2741 & 123.00 & 121.73 & -8.11 \\
\hline 369 & September & 114.3 & -1.0233 & 123.89 & 122.87 & -8.57 \\
\hline 370 & October & 112.44 & -0.8204 & 124.78 & 123.96 & -11.52 \\
\hline 371 & November & 111.47 & -0.6570 & 125.68 & 125.02 & -13.55 \\
\hline 372 & December & 113.11 & -0.5257 & 126.58 & 126.05 & -12.94 \\
\hline \multicolumn{2}{|c|}{ MAPE } & & & & & 8.64 \\
\hline
\end{tabular}

\section{Conclusion}

The Buys-Ballot procedure has shown that 1) the column mean and variances are not the same for the two models (Additive and Multiplicative), 2) when the trend is quadratic, the column variances mimic the shape of the trending series for both the additive and multiplicative models for the illustrative example. The result of the illustrative example using the data of Nigeria Spot component price of oil (US Dollar per Barrel) showed the additive model to be the appropriate model for decomposition of the series, based on the relationship between means and standard deviation. Finally, AR(2) was found to be adequate for the series under consideration; hence it was used to forecast. The comparison of the expected and observed prices showed no significant difference between them, using Mean Absolute Percentage Error (MAPE). Hence, we concluded that the additive model should be adopted when the trend component is quadratic (i.e., when the variation does not change as the level of the trend rises or falls).

\section{Conflicts of Interest}

The authors declare no conflicts of interest regarding the publication of this paper.

\section{References}

[1] Iwueze, I.S. and Nwogu, E.C. (2014) Framework for Choice of Model and Detection of Seasonal Effect in Time Series. Far East Journal of Theoretical Statistics, 48, 
45-66.

[2] Chatfield, C. (2004) The Analysis of Time Series: An Introduction. Chapman and Hall/CRC Press, Boca Raton.

[3] Iwueze, I.S., Nwogu, E.C., Ohakwe, J. and Ajaraogu, J.C. (2011) Uses of the Buys-Ballot Table in Time Series Analysis. Journal of Applied Mathematics, 2, 633-645. https://doi.org/10.4236/am.2011.25084

[4] Justo, P. and Rivera, M.A. (2010) Descriptive Analysis of Time Series Applied to Housing Prices in Spain. Management Mathematics for European Schools, 94342-CP-1-2001-DE-COMENIUS-C21.

[5] Wold, H. (1938) A Study in the Analysis of Stationary Time Series. 2nd Edition, Almqrist and Witsett, Stockholm.

[6] Buys-Ballot, C.H.D. (1847) Leo Claemert Periodiques de Temperature. Kemint et Fills, Utrecht.

[7] Akaike, H. (1974) A New Look at the Statistical Model Identification. IEEE Transactions on Automatic Control, 19, 716-723. https://doi.org/10.1109/TAC.1974.1100705

[8] Biu, O.E. and Iwueze, I.S. (2011) Application of Statistical Interventions Analysis to Oil and Gas Series in Niger Delta, Nigeria. Nigeria Annual International Conference and Exhibition, Abuja, 3-4. https://doi.org/10.2118/150744-MS

[9] Bradley, H., Christophe, T. and Denis, C. (2014) Standard Errors: A Review and Evaluation of Standard Errors Estimators Using Monte Carlo Simulations. The Quantitative Methods for Psychology, 10, 107.

https://doi.org/10.20982/tqmp.10.2.p107

[10] Smith, S. (1987) Tests of Accuracy and Bias for County Population Projections. Journal of the American Statistical Association, 82, 991-1003. https://doi.org/10.1080/01621459.1987.10478528

[11] Henry, G.A. (2010) Comparison of Akaike Information Criterion (AIC) and Bayesian Criterion (BIC) in Selection of an Asymmetric Price Relationship. Journal of Development and Agricultural Economics, 2, 001-006.

[12] Richard, A.S. (1994) Model Comparisons and $\mathrm{R}^{2}$. The American Statistician, 48, 113-117. https://doi.org/10.1080/00031305.1994.10476036

[13] Draper, N.R. and Smith, H. (1998) Applied Regression Analysis. John Wiley and Sons Inc., New York. https://doi.org/10.1002/9781118625590

[14] Ljung, G.M. and Box, G.E.P. (1978) On a Measure of Lack of Fit in Time Series Models. Biometrika, 65, 67-77. https://doi.org/10.1093/biomet/65.2.297 


\section{Appendix A}

Buys-Ballot Table for Nigeria Spot component price of oil (US Dollar per Barrel)

\begin{tabular}{|c|c|c|c|c|c|c|c|c|c|c|c|c|}
\hline Year & Jan & Feb & March & April & May & June & July & Aug & Sept & Oct & Nov & Dec \\
\hline 1983 & 31.65 & 29.38 & 28.35 & 29.6 & 29.76 & 30.13 & 30.66 & 31.04 & 30.51 & 29.93 & 29.31 & 28.78 \\
\hline 1984 & 29.32 & 29.7 & 30.05 & 30.11 & 29.93 & 29.33 & 28.1 & 28.4 & 28.48 & 28.15 & 27.8 & 27.31 \\
\hline 1985 & 27.09 & 27.89 & 28.04 & 27.98 & 26.85 & 26.66 & 26.97 & 27.79 & 28.09 & 28.87 & 29.89 & 27.25 \\
\hline 1986 & 22.38 & 17.4 & 14.21 & 12.5 & 14.41 & 12.09 & 9.82 & 13.91 & 14.11 & 13.6 & 14.49 & 16.12 \\
\hline 1987 & 18.4 & 17.43 & 18.2 & 18.25 & 18.84 & 19.01 & 20.1 & 19.1 & 18.55 & 19.03 & 18.05 & 17.28 \\
\hline 1988 & 16.85 & 15.8 & 15.02 & 16.76 & 16.57 & 15.38 & 15.39 & 14.9 & 13.34 & 12.59 & 13.33 & 15.59 \\
\hline 1989 & 17.27 & 17.23 & 19.18 & 20.49 & 18.96 & 17.85 & 18.14 & 16.87 & 17.93 & 19.26 & 19 & 20.28 \\
\hline 1990 & 21.64 & 20.04 & 18.73 & 17.1 & 16.75 & 15.46 & 17.86 & 28.6 & 35.31 & 36.95 & 33.55 & 28.85 \\
\hline 1991 & 24.55 & 20.25 & 19.36 & 19.41 & 19.39 & 18.53 & 19.81 & 20.18 & 21.03 & 22.81 & 21.74 & 18.91 \\
\hline 1992 & 18.6 & 18.63 & 18.22 & 19.75 & 20.55 & 21.76 & 20.94 & 20.46 & 20.86 & 20.95 & 19.91 & 18.83 \\
\hline 1993 & 17.8 & 19.13 & 19.42 & 19.24 & 19.01 & 18.25 & 17.51 & 17.22 & 16.44 & 17.08 & 15.66 & 13.96 \\
\hline 1994 & 14.74 & 14.5 & 14.4 & 15.55 & 16.72 & 17.21 & 17.85 & 16.98 & 16.01 & 16.89 & 17.58 & 15.94 \\
\hline 1995 & 16.92 & 17.54 & 17.24 & 18.84 & 18.71 & 17.58 & 15.95 & 16.25 & 17.11 & 16.56 & 17.19 & 18.44 \\
\hline 1996 & 18.55 & 18.64 & 20.64 & 21.43 & 19.58 & 18.73 & 20.04 & 21.15 & 22.95 & 24.74 & 23.11 & 24.53 \\
\hline 1997 & 24.04 & 21.65 & 19.39 & 17.82 & 19.6 & 17.95 & 18.95 & 19.04 & 18.89 & 19.98 & 19.36 & 17.34 \\
\hline 1998 & 15.25 & 14.11 & 13.14 & 13.51 & 14.46 & 11.89 & 12.01 & 12.14 & 13.59 & 12.66 & 11.15 & 9.96 \\
\hline 1999 & 11.33 & 10.24 & 12.56 & 15.44 & 15.45 & 15.86 & 19.28 & 20.44 & 22.9 & 22.3 & 24.8 & 25.86 \\
\hline 2000 & 25.41 & 28.36 & 27.54 & 22.91 & 27.87 & 29.86 & 28.75 & 29.06 & 32.65 & 30.67 & 32.86 & 25.47 \\
\hline 2001 & 25.43 & 27.4 & 24.35 & 25.43 & 28.51 & 28.06 & 24.81 & 25.41 & 25.98 & 20.6 & 18.92 & 18.78 \\
\hline 2002 & 19.65 & 20.3 & 23.76 & 25.79 & 25.1 & 23.98 & 25.93 & 26.94 & 28.46 & 27.9 & 24.07 & 29.27 \\
\hline 2003 & 30.78 & 32.33 & 30.83 & 25.27 & 25.78 & 27.46 & 28.39 & 29.79 & 27.47 & 29.59 & 28.93 & 29.64 \\
\hline 2004 & 30.94 & 30.47 & 33.34 & 33.74 & 37.87 & 35.6 & 38.08 & 42.55 & 43.56 & 49.91 & 43.6 & 39.08 \\
\hline 2005 & 44.01 & 45.43 & 53.15 & 53.18 & 50.23 & 55.93 & 58.4 & 65.49 & 65.6 & 60.74 & 57.18 & 57.91 \\
\hline 2006 & 64.04 & 62.12 & 63.8 & 71.8 & 71.75 & 70.22 & 75.49 & 75.29 & 63.87 & 58.75 & 60.32 & 64.28 \\
\hline 2007 & 56.18 & 59.58 & 64.6 & 70.01 & 70.03 & 74.45 & 79.21 & 73.34 & 79.87 & 85.6 & 95.32 & 93.55 \\
\hline 2008 & 94.85 & 96.98 & 106.68 & 112.52 & 126.55 & 136.44 & 137.64 & 116.93 & 100.48 & 74.57 & 56.11 & 43.1 \\
\hline 2009 & 45.44 & 45.07 & 49.7 & 52.24 & 57.87 & 69.55 & 66.31 & 73.84 & 68.74 & 74.41 & 77.96 & 75.68 \\
\hline 2010 & 77.39 & 75.04 & 80.4 & 86.14 & 76.87 & 76 & 77.04 & 78.82 & 79.65 & 84.35 & 86.83 & 93.08 \\
\hline 2011 & 98.1 & 105.66 & 116.75 & 127.12 & 118.88 & 117.27 & 119.69 & 112.41 & 115.63 & 113.09 & 114.21 & 110.71 \\
\hline 2012 & 113.08 & 122.36 & 127.98 & 122.36 & 112.87 & 97.19 & 104.24 & 114.63 & 114.06 & 113.31 & 110.91 & 111.19 \\
\hline 2013 & 115.41 & 118.69 & 110.57 & 105.17 & 105.83 & 106.12 & 110.21 & 113.62 & 114.3 & 112.44 & 111.47 & 113.11 \\
\hline
\end{tabular}

Source: Central Bank of Nigeria Statistical Bulletin 2014. 


\begin{tabular}{cccc}
\hline Months & Column Mean & Column Variances & Column Standard Deviation \\
\hline Jan & 38.29 & 921.26 & 30.35 \\
Feb & 38.69 & 1038.06 & 32.22 \\
Mar & 39.99 & 1157.33 & 34.02 \\
Apr & 40.89 & 1221.96 & 34.96 \\
May & 41.02 & 1168.89 & 34.19 \\
Jun & 41.03 & 1199.70 & 34.64 \\
Jul & 42.05 & 1279.42 & 35.77 \\
Aug & 42.66 & 1177.37 & 34.31 \\
Sept & 42.47 & 1092.76 & 33.06 \\
Oct & 41.88 & 1017.76 & 31.90 \\
Nov & 41.12 & 1032.33 & 32.13 \\
Dec & 40.33 & 1042.91 & 32.29 \\
\hline
\end{tabular}

\section{Appendix B. Minitab 17 Output}

\section{Regression Analysis: NSCPO versus $t$}

The regression equation is

$$
\mathrm{NSCPO}=-1.03+0.219 t
$$

\begin{tabular}{lllllll} 
Predictor & Coef & SE Coef & T & P & \\
Constant & -1.033 & 2.181 & -0.47 & 0.636 & \\
$t$ & 0.21910 & 0.01047 & 20.93 & 0.000 & \\
S = 20.6454 & R-Sq $=55.0 \%$ & R-Sq(adj) $=54.9 \%$ & \\
\multicolumn{7}{l}{ Analysis of Variance } \\
Source & DF & SS & MS & F & P \\
Regression & 1 & 186,648 & 186,648 & 437.90 & 0.000 \\
Residual Error & 358 & 152,592 & 426 & & \\
Total & 359 & 339,240 & & &
\end{tabular}

\section{Regression Analysis: NSCPO versus $t, t^{2}$}

The regression equation is

\begin{tabular}{llllll} 
& \multicolumn{5}{c}{ NSCPO $=37.8-0.424 t+0.00178 t^{2}$} \\
Predictor & Coef & SE Coef & T & P \\
Constant & 37.781 & 1.803 & 20.95 & 0.000 \\
$t$ & -0.42423 & 0.02307 & -18.39 & 0.000 \\
$t^{2}$ & 0.00178209 & 0.00006188 & 28.80 & 0.000 \\
S = 11.3404 & R-Sq $=86.5 \%$ & R-Sq(adj) $=86.4 \%$ \\
Analysis of Variance & & & & \\
Source & DF & SS & MS & F & P \\
Regression & 2 & 293,328 & 146,664 & 1140.43 & 0.000 \\
Residual Error & 357 & 44,912 & 129 & & \\
Total & 359 & 339,240 & & &
\end{tabular}

\section{Regression Analysis: NSCPO versus $t, t^{2}, t^{3}$}


The regression equation is

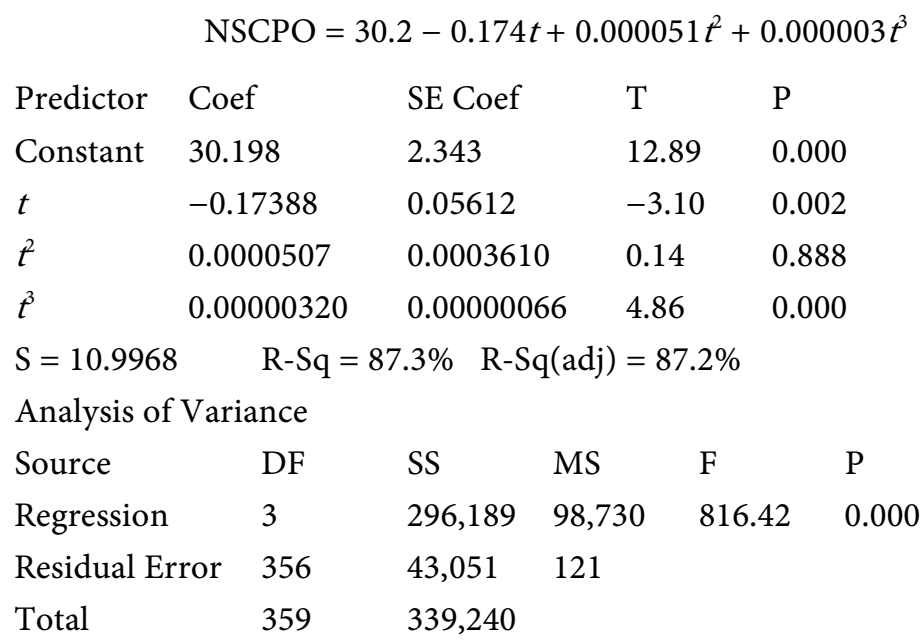

Regression Analysis: NSCPO versus $t, t^{2}, t^{3}, t^{4}$

The regression equation is

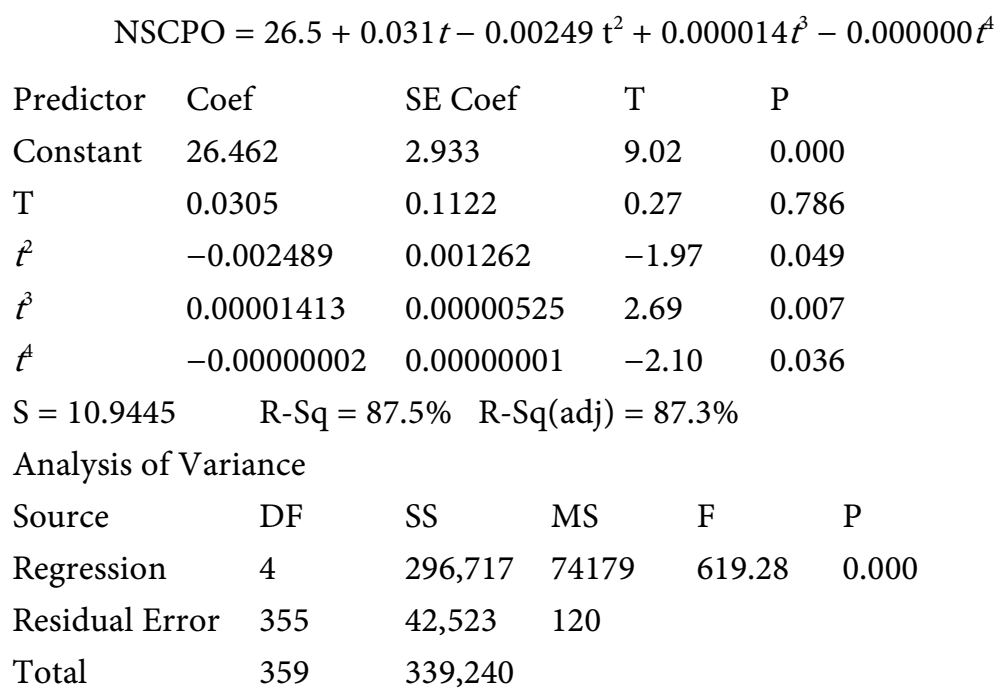

\section{Appendix C}

One-Sample T: Additive $Y_{t}$

Test of $\mathrm{mu}=0 \mathrm{vs}$ not $=0$

\begin{tabular}{lccccccc}
\hline Variable & $\mathrm{N}$ & Mean & StDev & SE Mean & $95 \% \mathrm{CI}$ & $\mathrm{T}$ & $\mathrm{P}$ \\
\hline 99Additive $\mathrm{Yt}$ & 360 & -0.000001 & 11.308743 & 0.596023 & $(-1.172136,1.172135)$ & $-9.32 \times 10^{-7}$ & 1.000
\end{tabular}

\section{Appendix D}

Trend Analysis for NSCPO (Quadratic Trend $\hat{X}_{t}$ )

$\begin{array}{ll}\text { Data } & \text { NSCPO } \\ \text { Length } & 360 \\ \text { NMissing } & 0\end{array}$

Fitted Trend Equation 


$$
Y_{t}=37.7815-0.424231 t+0.00178209 t^{2}
$$

\begin{tabular}{ll} 
Accuracy & \multicolumn{1}{l}{ Measures } \\
MAPE & 24.532 \\
MAD & 7.733 \\
MSD & 127.532 \\
Forecasts & for 2013 \\
Period & Forecast \\
May & 116.878 \\
Jun & 117.742 \\
Jul & 118.610 \\
Aug & 119.481 \\
Sep & 120.356 \\
Oct & 121.235 \\
Nov & 122.117 \\
Dec & 123.002 \\
Jan & 123.892 \\
Feb & 124.784 \\
Mar & 125.681 \\
Apr & 126.580
\end{tabular}

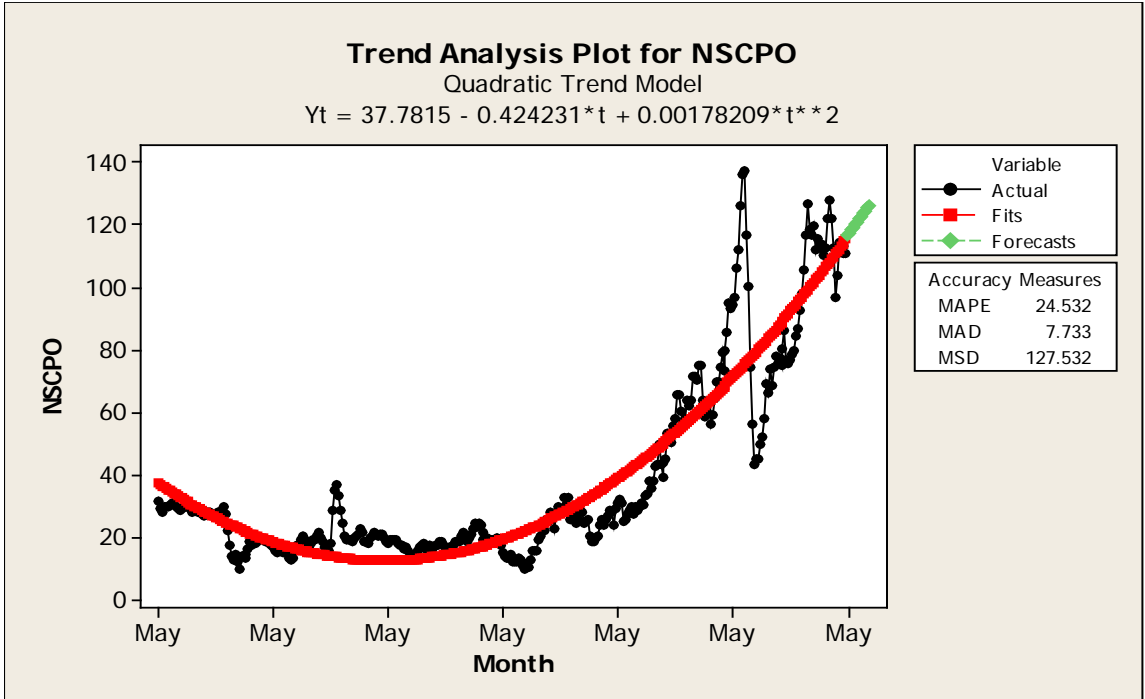

AR(2) $Y_{t}$ Forecasts for 2013

ARIMA Model: Additive $Y_{t}$

Final Estimates of Parameters

$\begin{array}{llllll}\text { Type } & & \text { Coef } & \text { SE Coef } & \text { T } & \text { P } \\ \text { AR } & 1 & 1.3389 & 0.0477 & 28.08 & 0.000 \\ \text { AR } & 2 & -0.4315 & 0.0477 & -9.05 & 0.000\end{array}$

Number of observations: 360

Residuals: $\quad$ SS $=4685.13$ (backforecasts excluded)

$$
\mathrm{MS}=13.09 \quad \mathrm{DF}=358
$$


Modified Box-Pierce (Ljung-Box) Chi-Square statistic

Lag 12 24

36 48

Chi-Square 14.8 $\begin{array}{lll}32.8 & 65.3 \quad 78.0\end{array}$

DF

P-Value

0.141

22

34

46

Forecasts from period 360

95 Percent Limits

$\begin{array}{cllll}\text { Period } & \text { Forecast } & \text { Lower } & \text { Upper } & \text { Actual } \\ 361 & -4.6296 & -11.7215 & 2.4623 & \\ 362 & -4.1159 & -15.9676 & 7.7357 \\ 363 & -3.5134 & -18.7995 & 11.7726 & \\ 364 & -2.9284 & -20.5811 & 14.7243 & \\ 365 & -2.4050 & -21.6465 & 16.8365 & \\ 366 & -1.9566 & -22.2478 & 18.3346 \\ 367 & -1.5821 & -22.5595 & 19.3953 \\ 368 & -1.2741 & -22.6970 & 20.1487 \\ 369 & -1.0233 & -22.7339 & 20.6872 \\ 370 & -0.8204 & -22.7162 & 21.0753 \\ 371 & -0.6570 & -22.6716 & 21.3577 & \\ 372 & -0.5257 & -22.6165 & 21.5652 & \end{array}$

